\title{
Brand Guideline
}

\author{
Emmanuel Mogaji \\ University of Greenwich, London, UK \\ e.o.mogaji@greenwich.ac.uk
}

\begin{abstract}
Companies spend a considerable amount of money to develop their brand identities. It is not a cheap commercial endeavour. Given the importance of brand identities as intangible assets for organisations, the ability to strategically manage them is critical. Extant research is predominantly based on theoretical models and concepts of branding, yet no attempt has been made to develop an understanding of the consistent communication of brand identities. This paper provides background information on brand guidelines, the benefit, content and user of brand guidelines. Researchers and students in brand management will find this relevant for brand identity, brand integration and brand architecture studies and research. Ideas for future research studies have also been presented. Likewise, brand managers may also find these relevant, especially those working with smaller brands which do not have a guideline and those with established brands looking at properly documenting their brand architecture and identities.
\end{abstract}

\section{Introduction}

Companies spend a considerable amount of money to develop their brand identities. It is not a cheap commercial endeavour. In 2000, Landor, a famous San Francisco based design agency replaced BP's their logo with a new design, the "Helios" - the name of the Greek sun god costing over $\$ 200$ million. In 2008, Arnell group redesigned the Pepsi logo costing one million dollars (Edwards, 2009). This huge cost is not only limited to companies. London 2012 Olympics logo was designed by Wolff Olins, a London-based brand consultancy firm at the cost of $\$ 625,000$.

Given the importance of brand identities as intangible assets for organisations, the ability to strategically manage them is critical (Keller, 2014). Extant research is predominantly based on theoretical models and concepts of branding, yet no attempt has been made to develop an understanding of the consistent communication of brand identities. For brands to be trusted, a consisted continuous identity is required (Burmann \& Zeplin, 2005) and a coherent brand architecture contributes to the companies' overall marketing strategy (Sanchez, 2004). 
It is essential to communicate in a clear, consistent manner across different touchpoints as this is necessary to build an efficient and powerful brand, and to achieve this, a brand guideline is essential. However, there is little conceptual and theoretical understanding of this document. The primary purpose of this paper is to provide background information on brand guidelines, for the benefit of researchers with interest in brand communications, design and management and for the benefit of practitioners who wants to develop a better understanding and need for a brand guideline.

\section{What is a Brand Guideline?}

A brand guideline is a document that provides detailed information about the brand. It highlights the brand values and identities, set out detailed information about the brand identities, set the rule about the composition, design and general use of a brand identity and present examples and templates of marketing collaterals.

The brand guideline is also called the brand book, brand bible or style guide. Andrys (2019) described it as the owner's manual on how to "use" their brands. It explains how Organisations wants their stakeholders to see their brands. This guide influences both internal and external communications, marketing and advertising. It is an attempt to properly document things about the brand and making it available for different stakeholders that might need it.

\section{Who prepares the Guideline?}

The Brand guideline should be prepared by whoever developed the brand. Depending on the size of the Organisation, Often, Brand agencies are responsible for developing the different elements of a brand, especially after rebranding and they are responsible for developing the guidelines for the Organisation that employed them. Landor who developed the BP brand (Landor, n.d.) and Wolff Olins who developed the London 2012 Olympics logo (Wolff Olins, n.d.) will be responsible for the brand guidelines. It should be part of the project's deliverables.

For smaller brands or startup, the graphics designer who developed the brand identities should make the guidelines available. Artist Simon Oxley designed the now-famous Twitter bird logo which was Twitter bought on iStockphoto for $\$ 15$, then Twitter was an upcoming start-up company (Van Buskirk, 2009) but the bird has been redesigned, the new design is presented under their brand resources on their website (Twitter, 2019).

If the business owner or the company has developed the brand identity, it is essential to document the creative decisions they have made. Microsoft changes its logo for the first time in 25 years; the logo developed mainly by Microsoft employees (Allison, 2012). 
That is an in-house design, and they must prepare their identity guideline as they expect various stakeholders around the world knows about the new brand and how it should and should not be used.

\section{Who uses the Guideline?}

This document is prepared for those working with the brands. It serves as a reference for everyone who engages with the brand, telling them exactly how to communicate your brand. The users can be categorised into two groups.

\section{Internal Users}

These are employees of the companies working across different department and the different global office. For staff designing a letterhead in America should use the same design as staff in Europe. This also cuts across staff PowerPoint presentation slides, complimentary cards and even email signatures. When In-house team are creating an advert, they will also need the brand guideline. This guide also influences the internal communications within the organisation using examples of editorial guidelines and 'tone of voice'. Staff must understand clearly how to represent the brand.

\section{External Users}

They are vendors, contractors or design agencies working with the brand. They may not have a full understanding of the brand; the brand guidelines provide that information from the brand's perspective and help them communicate the brand effectively. The documents guide these external users through the core elements of the brand, assisting them designing and producing compelling communications which align to the brand's identity.

\section{What is the Content?}

Brand Guidelines can run into hundreds of pages depending on the design and amount of content made available. It is essential that each elements of the brand is well defined to keep the brand consistent, the length can vary but it is good to keep them coincide enough for users to understand and follow the guideline. These guidelines are also being made available online on the companies' websites. Irrespective of the size or where it is being deposited, three basic features are expected in a brand guideline.

\section{Brand Information}

The document should give an overview of your brand. If it was prepared after a rebranding exercise, the brand guideline should contain a background into the need for the rebranding as well. The guidelines provide further insight into why they have decided to rebrand and come up with a new identity which warrants the need for the guideline. It also reiterates what the brand stands for - its values, vision and philosophy. The 
guideline should also communicate examples of editorial guidelines and 'tone of voice' this is how companies wants their brand to be heard when communicating. The tone of voice also involves how written communication should be structured. A distinctive and consistent tone of voice helps the brand remain consistent, it builds recognition and enhances understanding between all stakeholders. The brand uses the document to remind the readers about what lies ahead for the brand. All these are the abstract brand identities that will be physically presented in the next section.

\section{Brand Identities}

The brand identity is the visual elements which need to be explicitly presented. These identities are generally classified into four groups.

\section{Logo}

This is a combination of two components - the symbol and the logotype. Brand guideline clear display what these features are. Users are expected to use the logo in all communications and to stick to the arrangement with the exception in some cases like social media profile where only the icon will be used. The various arrangement of the logo is also presented, sometimes in black and white or on a darker background. Brands take pride in the logo and will always emphasise an 'Exclusion Zone' around the logo where no text or image will interfere. This is the minimum clear space that must surround the logo. This zone ensures that the impact and legibility of the logo are not compromised in the application. Users are also warned about 'Logo Misuse' as brands want a consistent appearance of their identity. They warned that the logo should not be misinterpreted, modified, or added to. No attempt should be made to alter the logo in any way. They expect the logo's orientation, colour and composition to remain as indicated in the document.

\section{Colour}

The consistent use of these colours is encouraged by the brands as it contributes to a cohesive and harmonious look across all relevant media. To achieve this, colour palettes are provided as part of the brand identity, and these are identified explicitly with various colour coding systems such as the Pantone ${ }^{\circledR}$ colour system, the international standard for producing colours, CMYK (Cyan, Magenta, Yellow, Key/Black) for print, RGB (Red, Green, Blue) for screen and hexadecimal values for websites. To further ensure that creative freedom, the brand will also advise users on different colour combinations within the colour palettes. For some brands that have trademarked their colours or have a specific shade of colour they use, information about these colours is also presented. For example, both Queen's University Belfast and Netflix have red as their primary colour, but they are of different shades. Queen's University Belfast has a primary colour that they describe as Queen's Red - Pantone 185c (Queens, n.d.) while Netflix described theirs as Netflix Red - PANTONE 1795 C (Netflix, n.d.). This detailed information is necessary to ensure that brand differentiation and consistency 


\section{Typography}

The organisation often acknowledges that type is more than a design element. They see it as a creative element which expresses who they are. The typographic principles are often based on function, format and purpose. These fonts could be bespoke fonts, specially designed for the brand and therefore any user, either internal or external will have to get the font from the company. Cisco showcased their clean, modern and simple font, specially created for them (Cisco, 2019). There commercial fonts which external users may have to buy and use if they want to with the brand. There are also system fonts which might be used when bespoke and commercial fonts are not available. These fonts are available on most word processing software and are free to use, so they do not require a font licence. Information on the typography also includes size and weight, Case, Line spacing, Letter spacing (also known as tracking) and Justification. Some brands can also recommend specific fonts for use around the world, as far as it aligns with their main font. Non-English language layouts are also catered for, especially Arabic where right alignment will replace the left-alignment. Some specific rules are also often presented with regards to the typography such as not adding drop shadows, not stretching the type horizontally or vertically and avoiding hyphenation in general, and especially in headlines.

\section{Image}

Information regarding the type, composition and quality of images to use are provided in the guidelines. Images are considered one of the brands' identity to effectively engage with the specific audience. Companies expect those working with their brands to use the image to tell a story and give the right impression. Specifically, some brands request for reportage-style photography that embodies a photo-journalistic eye to capture pure moments. Users are warned to avoid purchasing stock photography whenever possible as brands want specially commissioned images to convey their brand identities as it makes its unique, not see elsewhere and makes the message more coherent. I Love New York Brand Guidelines specially stated that images used should be photographs taken in the New York State. Some brands (Cisco, 2019), do have a vast library of approved photos, freely available for staff and external users, these images can be used legally, anywhere in the world, in any media. Rules such as avoiding emotionless images, avoiding images that do not tell a story, or avoiding images where models are posing are also presented in the guidelines. Some brands also support the use of illustrations where images are not available or if there is a need to create an even more distinctive impression, but it should still be coherent with the overall brand identity. The use of icons is also allowed for some brands, but they expect it to be predominantly used in digital applications to aid navigation.

\section{Brand Integration}

Brands give examples of ways in which their brands can be adequately and consistently integrated across different media. They demonstrate how different brand identities can be combined to make effective communication. This also includes demonstrating the use 
of the grid lines as an essential organisational tool in visual identity design. The brands believe that using these examples and guides provided; it helps deliver their messages in a clean, simple, and direct way. This integration also includes the sample layout and template for marketing collateral, Stationery Items, Business Card, Compliment Slip, Envelope, Pull-up Stand, Building Entrance Plaque, Wayfinding Signage, Merchandise, Social Media, Microsoft powerpoint presentations and Website Elements. This list is inexhaustible depending on how large the brand is and how much touch point they need to integrate and reinforce their new brands.

\section{Why is the Guideline important?}

Imagine buying a new car without having the manual to know about the various function in the car. Even though if you do not use the manual every day, you know its somewhere and you can check it if need be. So also, is the brand guideline. It is needed to accurately identify and document the different brand elements of a company. This understanding helps in making great internal and external communications.

Also, it is important to note that the brand agency who developed the brand identities may no longer be around and it will be the duty of another agency to keep working on the brand. Omnicom's Arnell Group, world-renowned brand strategy, marketing communications, and design firm who redesigned the Pepsi Logo closed their studio in 2013 (Parekh, 2013). It is crucial for brands to have and keep this record.

The brand guideline is the property of the brand owner, and it is needed as documentation and official representation of the brand elements. This can also be useful for future brand identity revisions. It is essential to know what the brand has documented and how to move on from there. For consistency sake, the guideline offers a central hub for all the users working with the brand to get the information needed. It is essential that the right shade of red is used across the media, irrespective of screen or country.

The availability of the brand guidelines also helps large organisation appear consistent across different touchpoints. Wherever the brand operates, the same message is passed. This also help both internal and external users working on the brand; they do not have to stress themselves working on how to communicate effectively, the brand guidelines are there to help them.

\section{Research on Brand Guidelines}

Despite the amount of information inherent in brand guidelines, theoretical exploration of this document is scarce, despite academic advancement on other brand concept, brand guidelines have been neglected. Mogaji (2018) thematically analysed UK Universities brand guidelines; the study highlights how university as a body sees their brand and wants it conveyed. There are still many research opportunities for brand communication researchers as they explore brand guidelines. 
The document provides insight into brand values and the brand elements, a thematic and content analysis could offer a deeper insight into how brands in an industry are presenting their brands; their creative elements such as logo, types and colours can also be further researched, perhaps if there are differences in the use of these elements.

Theoretically, this can also be linked to Corporate Identity Model (Melewar \& Saunders , 1998) which consists of a corporate name, logotype and symbol of the organisation. Previous studies on corporate identity have been from the perspective of users such as students and customers (Walsh, et al., 2010; Ewing, et al., 2007) and not from the perspective of the brand owners. This is one of the gaps that are worth exploring: to understand brand identity from the brand's point of view through the analysis of their brand guidelines.

\section{Conclusion}

This paper has attempted to provide a holistic understanding about the brand guideline. Acknowledging the cost involved in designing brand identities, guidelines on how best to use it is essential. A company should not invest so much money on a project and not have a manual or guide on how to make the best use of the outcomes. The brand guideline is considered one of the rebranding deliverables that is prepared for the brand by the brand agency. It is essential that brand owners have this at the end of the project.

It is also argued that the brand lines should be made publicly available, at least made available on request for anyone who is interested in knowing more about the brand, surely any trade secret should be excluded from brand guidelines. The document should be available online on the company's website or a downloadable PDF version. The online version can also allow for sample video and audio as brand identities. On the note of availability, it is vital that the document is dated, and the version number should be presented.

Both internal and external users should be made aware of the brand guidelines, it makes no use to create the identity and the guideline and not to make it available. Likewise, efforts should be made towards a consistent use, the paper also argues the need for Brand police, to surely report any situation in which the brand is not properly integrated, and actions should be put in place to address such issues. For example, if staff sees that the logo is not used correctly by a vendor in another country, there should be an avenue to report it.

Brand guidelines are not just limited to big corporations, small business and start-ups can also have their brand guiltiness, albeit not very detailed but at least the logo, the shade of colour and font being used, these three basics are essential to ensure consistency. Also, individual brands can also have their brand guidelines, Celebrities, sports personalities and entertainers who have a recognised brand can also have their brand identities documented in a brand guideline. 
This has been an attempt to theoretically presents this insight on brand guidelines as little academic insight on this matter, Researchers and students in brand management will find this relevant for brand identity, brand integration and brand architecture studies and research. Ideas for future research studies have also been presented. Likewise, brand managers may also find these relevant, especially those working with smaller brands which do not have a guideline and those with established brands looking at properly documenting their brand architecture and identities.

\section{References}

Allison, M., 2012. New Microsoft logo gets mixed reviews. [Online]

Available at:

http://old.seattletimes.com/html/businesstechnology/2018979469 microsoftreaxxml. html [Accessed 112019 ].

Andrys, S., 2019. 36 Great Brand Guidelines Examples. [Online]

Available at: https://www.contentharmony.com/blog/great-brand-guidelines/

Burmann, C. \& Zeplin, S., 2005. Building brand commitment: A behavioural approach to internal brand management. Journal of Brand Management, 12(4), pp. 279-300.

Cisco, 2019. Brand Centre. [Online] Available at:

https://www.cisco.com/c/m/en us/about/brand-center/copyright-use/copyrightmaterial-guidelines/interactive-brand-book.html\#16 [Accessed 11 2019].

Edwards, J., 2009. Pepsi's Nonsensical Logo Redesign Document: \$1 Million for This? [Online] Available at: https://www.cbsnews.com/news/pepsis-nonsensicallogo-redesign-document-1-million-for-this/[Accessed 11 2019].

Ewing, M., Jevons, C. \& Jevons, C., 2007. Aesthetic theory and logo design: examining consumer response to proportion across cultures. International Marketing Review, 24(3), pp. 457-473.

Keller, K. L., 2014. Designing and implementing brand architecture strategies. Journal of Brand Management, 21(9), pp. 702-715.

Landor, n.d. BP: Brand as a beacon of change. [Online]

Available at: https://landor.com/work/bp [Accessed 11 2019].

Melewar, T. C. \& Saunders , J., 1998. Global corporate visual identity systems:

Standardization, control and benefits. International Marketing Review, 15(4), pp. 291308. 
Mogaji, E., 2018. UK Universities Corporate Visual Identities. Stirli, Academy of Marketing Annual Conference Proceedings 3rd-5th July Stirling University. https://doi.org/10.31124/advance.7203269.v1

Netflix, n.d. Brand Assets. [Online]

Available at: https://brand.netflix.com/en/assets/

[Accessed 11 2019].

Parekh, R., 2013. END OF AN ERA: OMNICOM'S ARNELL GROUP TO CLOSE. [Online]

Available at: https://adage.com/article/agency-news/end-era-omnicom-s-arnell-group$\underline{\text { close } / 240387 /}$

[Accessed 11 2019].

Queens, n.d. Brand Guidelines. [Online]

Available at:

https://www.qub.ac.uk/sites/StaffGateway/Filestore/Filetoupload,680854,en.pdf [Accessed 11 2019].

Sanchez, R., 2004. Conceptual analysis of brand architecture and relationships within product categories. Journal of Brand Management, 11(3), pp. 233-247.

Twitter, 2019. Brand Resources. [Online]

Available at: https://about.twitter.com/en_gb/company/brand-resources.html [Accessed 11 2019].

Van Buskirk, E., 2009. Twitter Paid $\$ 6$ or Less for Crowdsourced 'Birdie' Graphic. [Online]

Available at: https://www.wired.com/2009/03/twitter-designe/

[Accessed 11 2019].

Walsh, M. F., Winterich, K. P. \& Mitt, V., 2010. Do logo redesigns help or hurt your brand? The role of brand commitment. Journal of Product \& Brand Management, 19(2), pp. 76-84.

Wolff Olins, n.d. London 2012. [Online]

Available at: https://www.wolffolins.com/case-studies/london-2012/

[Accessed 11 2019]. 